\title{
Innovative Reform in Teaching of Foundation of Machine Manufacturing Technology Course
}

\author{
Wen-Bin He, Xiao-Ke Li, Jin-Guang Du \\ School of Mechanical and Electrical Engineering \\ Zhengzhou University of Light Industry \\ Zhengzhou, China \\ 344365857@qq.com
}

\author{
Yang Cao, Kun Liu, Jun Ma* \\ School of Mechanical and Electrical Engineering \\ Zhengzhou University of Light Industry \\ Zhengzhou, China \\ 2008039@zzuli.edu.cn \\ *The Corresponding Author
}

\begin{abstract}
Foundation of machine manufacturing technology is a very important course for students majoring in machinery. To overcome the problems existing in the teaching process of this course, an in-depth investigation is conducted and corresponding improvement adjustments are given. Furthermore, the teaching reform is explored and a more reasonable course teaching system is constructed. From teaching means, teaching arrangement, assessment method and teaching content, this paper discusses how to improve the teaching quality of the foundation of machine manufacturing technology course. The multi-directional and open practice teaching platform proposed in this paper can be a useful tool to satisfy the needs of application-oriented personnel training.
\end{abstract}

Keywords-Foundation of machine manufacturing technology; Curriculum system; Course reform

\section{INTRODUCTION}

The curriculum is the heart of college education, the basic basis of personnel training and teaching work, and also the key factor to affect and even determine the quality of education and teaching. Under the background that improving the quality of education in an all-round way has become the national strategy, the will of the government and the consensus of the society, the status, the value and the function of the curriculum are becoming more and more prominent, which has attracted the unprecedented attention of colleges and universities. On the practical level, colleges and universities are also making great efforts to continuously promote curriculum reform. It can be said that curriculum reform is one of the most active parts of the whole higher education reform. Starting from the problems existing in the teaching of the foundation of machine manufacturing technology, this paper puts forward some innovative solutions to the teaching reform.

\section{MAIN PROBLEMS}

\section{A. An unreasonable application of teaching methods}

With the development of science and technology, many advanced teaching methods emerge, such as projector, voice equipment, multimedia, various teaching apps, etc. The main purpose of introducing these means into teaching is to simplify the teaching content, enhance the observation and understanding, master the teaching materials, and finally improve the teaching quality. At present, there are two extremes in the teaching process. One is that some teachers, especially some young teachers with less experience, use these devices as a tool to reduce the task of preparing lessons. Many teachers put all the teaching content into PPT to reduce the time of preparing lessons. The other is that some teachers are too exclusive of these teaching methods and think their application will distract students' attention. Therefore, they still adopt the traditional teaching method, such as lecture and blackboard writing, so that the teaching process is too rigid and the classroom atmosphere is not so active. Moreover, many abstract things, such as the structure of machine tools and the processing process of parts, is difficult to understand and the students gradually lose their learning enthusiasm.

\section{B. Disjointed theory and practice}

Foundation of machine manufacturing technology is a professional basic course, which is closely related to engineering practice. The process of processing involves much knowledge, such as various phenomena, performance, and parameters of various equipment, preparation of process procedures, advantages and disadvantages of different process routes, and possible consequences in production, etc. Students must combine a lot of practical experience to better understand. Many operation steps and principles sound inexplicable, but it is very easy to understand as long as they go to the workshop. The existing teaching mode separates theory and practice in time and space. First, complete the theory before practice, or complete the practice before theoretical learning [1]. The lack of engineering practice makes theoretical teaching very difficult for students to understand due to their lack of perceptual knowledge, and they are in a state of confusion. Engineering practice without theoretical support will inevitably stop at a lower level to acquire some perceptual knowledge and operation skills. Although the course is highly practical, the fewer class hours make it difficult to complete the teaching syllabus with the target satisfaction of cultivating students' engineering consciousness, application ability and innovation ability to integrate theory with practice.

\section{Defects in the assessment method}

At present, most colleges and universities evaluate the learning effect of students' courses mainly by the theory examination, and most of the examination methods are memory knowledge points. The lack of assessment for the ability to analyze and solve problems leads to the students' emphasis on theory and the practical application is neglected in 
the learning process. The knowledge points are forgotten soon after the examination is finished, which is not conducive to the cultivation of application-oriented talents [2]. Traditional course examination is generally set in the final examination, the content and form of the examination are rigid, except for the slight changes in the types of questions over the years, which leads to students' simple pursuit of scores in the learning process. The content related to the examination is valued, and the content unrelated to the examination is ignored. Some students don't listen to the class at ordinary times, and even don't turn over the book. They can finish the course by memorizing some concepts, terms and simple theories in the hard endorsement with the help of "cramming temporarily" before the examination. Thus, teachers can only judge students' abilities from a simple score, which leads to the frequent occurrence of "high score and low energy" or "high energy and low score", which restricts the overall and balanced development of students in the future. In this way, after the students finished the course, they learned nothing and got nothing.

\section{Relatively old teaching content}

The foundation of machine manufacturing technology mainly involves the introduction of traditional knowledge, but as a basic course of mechanical specialty, many contents have not kept up with the development of the mechanical manufacturing industry. For example, some textbooks still explain the gear transmission system of machine tools with great length. In fact, these machine tools have been replaced by numerical control machine tools. The teaching material emphasizes the integrity and systematicness of theory and knowledge, but the application of knowledge is often ignored. It lacks the knowledge application in practical engineering problems [3], which leads some students to think that the course is useless [4]. Although some responsible teachers use various methods such as physical models and animations to satisfy the teaching needs of different chapters, they still can't arouse students' interest. Students have no initiative in learning, so it is difficult to achieve better teaching results.

\section{SOLUTIONS}

\section{A. Effective selection of flexible teaching methods}

In order to ensure the teaching quality, flexible teaching methods should be adopted. For example, when explaining the machine tool, tool, fixture and other knowledge to students, if only relying on the theory, students can't fully understand. But by using intuitive teaching, on-site teaching, and audio-visual teaching, the problem of hard to explain on the blackboard can be solved in a short time. In addition, teaching can be carried out through discussion, research and heuristic methods to create an interactive teaching environment between teachers and students, which can enhance students' enthusiasm and enthusiasm for learning [5]. The interactive teaching method is a dynamic process of communication, consultation, and discussion between teachers and students in teaching. On the basis of equality, mutual listening, mutual acceptance, and mutual honesty, it achieves the collision and blending of different views through rational persuasion, so as to better simulate the initiative of both sides of teaching. When teaching, teachers should adjust it according to the actual situation of students. They should not only pay attention to the "teaching" of teachers, but also pay attention to the "learning" of students. Teachers and students are the two most important factors in classroom teaching. Only when the two aspects are coordinated, can classroom teaching be effective. According to students' ability and course characteristics, teachers can build a digital teaching model through some advanced simulation software, so that students can visualize abstract content through observation and dynamic simulation display, which is very useful for understanding and memory. The form of a flipped classroom can also be adopted in the teaching process. Making students become the master of the course, combined with the project-driven teaching, a discussion-based teaching mode finally can be built [6]. In short, through continuous teaching exploration, the foundation of machine manufacturing technology has achieved certain results. However, reform and innovation is a complex process. The teaching methods are diverse; each method has its scope of application and unique function. The appropriate teaching methods should be selected based on different teaching purposes, teaching content, student characteristics and teachers' own conditions.

\section{B. Emphasizing the role of practice in the teaching process}

The foundation of machine manufacturing technology is different from the pure theory course, which has strong practicality and application. The effect of practice plays an important role in teaching quality. Through the schools existing practice bases, the theory teaching can be combined with the production practice, which can greatly enhance the students' sense of participation and engineering ability. By means of parallel theory teaching and on-site teaching, not only theoretical knowledge can be learned, but also the ability to solve practical engineering problems can be improved greatly. Finally, the theoretical knowledge can be sublimated to the application level, thus the teaching quality and teaching level of the course can be improved. Production practice belongs to the practice link in the foundation of machine manufacturing technology, which is the most important part. It is directly related to the ability to improve students' practice ability, problem-solving ability and judgment ability. In order to full use of the knowledge learned in practice, colleges and universities should constantly improve the quality of students' practice and strengthen their relationship with classroom teaching. Engineering application practice is an important practical teaching link to cultivate students' ability to combine theory with practice. Students can participate in the production process of spare parts on the production site, so as to lay a solid foundation for their future work [7].

\section{Adopting reasonable assessment methods}

It is difficult to assess a student's ability through the final exam. Therefore, a more reasonable way should be chosen to assess the comprehensive ability of students. In this way, students are no longer forced to study for the purpose of passing the examination, but develop a consciously, diligently and actively learning the habit. To truly improve the learning ability and teaching quality, the students can be assessed in classroom teaching, curriculum design, practice, and defense. In order to fully reflect students' learning achievements, using the results of one test as the sole evaluation basis is not advisable. A variety of evaluation modes to test teachers' 
teaching achievements and students' knowledge mastery should be adopted. And more attention should be paid to the combination of process evaluation and result evaluation. Moreover, various assessment methods should be adopted for various students in accordance with their aptitude, so that students can thoroughly grasp the course [8].

\section{Strengthening the dynamic combination of teaching content and professional development}

With the rapid development of science and technology, new mechanical manufacturing methods are emerging. In order to improve students' interest in learning, teachers should collect the latest development trends of the subject in combination with specific teaching contents. In addition, students can be advised to collect cutting-edge technology after class to cultivate their self-study ability. The content of the course should keep up with the actual needs of enterprises. Before determining the content of the course, colleges should actually understand the current advanced technology and requirements of relevant enterprises. After that, the content of the course should closely link with the production practice. Students can also be organized to visit the production workshop, which can deepen students' understanding of the course content. On the other hand, many teachers, who are rich in theoretical knowledge but lack of practical production experience, can only "talk on paper". Therefore, in the process of building the teaching staff, the course teaching and practice training should be arranged reasonably. Also, the teachers can be encouraged to participate in project development and other ways to enhance their comprehensive ability. On the basis of the long-term accumulated teaching experience, the teaching contents are processed and sorted out in the teaching process, and taught to students in a unique way. Furthermore, relevant extra-curricular knowledge can be supplemented to keep the teaching content fresh and sense of the times, so that students will not feel boring and inflexible. Using this way, students can understand the most cutting-edge things in society and always walk in the forefront of the market.

The process design of the product has relativity and time domain. The so-called relativity is suitable for the technical requirements of parts, the quality standards of products and the actual situation of enterprises. The so-called time domain is that some structures in the past can't be processed, but now it is easy to manufacture. Some structures cannot be processed now and may be manufactured in the future. At this stage, because advanced manufacturing technology has combined with the actual needs of production in the process of mechanical manufacturing, a large number of new processes and technologies have emerged, which are difficult to reflect in time in textbooks. Teachers should also keep learning, update knowledge and concepts, supplement and update teaching courseware regularly, and explain relevant contents for students, so that students can understand the development of advanced machine manufacturing technology.

\section{E. Construction of new teaching method}

Through continuous teaching exploration, the foundation of machine manufacturing technology has achieved certain results. But the teaching of the foundation of machine manufacturing technology is a complex process with various teaching methods. Each method has its scope of application and unique role. Therefore, it requires a more dynamic interaction between teachers and students. Teachers should constantly improve the teaching methods according to the teaching content, students' characteristics and teachers' own conditions [9]. In order to improve the teaching quality, teachers should possess a vision of keeping pace with the times, and constantly update the teaching mode and teaching concept so that students can be more interested in and actively learn the course.

\section{CONCLUSION}

In view of the problems existing in the teaching of the foundation of machine manufacturing technology, this paper discusses the content, teaching methods and assessment mode, and puts forward specific measures for the teaching reform of the foundation of machine manufacturing technology, which provides a solid theoretical basis for the students' following professional study and future work. As the main course of mechanical undergraduate education, the foundation of machine manufacturing technology must adapt to the development of the times, and constantly update the teaching content in order to keep its vitality. This paper makes a preliminary discussion on the main problems and solutions in the teaching process of the foundation of machine manufacturing technology. In the future, the efforts of teachers, schools and all aspects of society should be combined to thoroughly solve the current difficulties.

\section{REFERENCES}

[1]. Zhu Qing-shi. "Progress in green chemistry”. University Chemistry, vol.12, A6, pp.7-11, 1997.

[2]. Tao Liang, Chen Juan, Pan Ke-Qiang, Ji Bin, "The discussion and exploration of teaching reform on the course of mechanical manufacturing technology fundamentals”. Education Teaching Forum, vol. 39, pp.154-155, September 2018. (In Chinese)

[3]. Sui Rong-juan. "Application of finite element simulation technology in teaching fundamentals of mechanical". China Modern Education Equipment, vol. 15, pp.25-26, August 2014. (In Chinese)

[4]. Luo Xiao-Lin, Bao Jia-fu. "The content reformation in the basics of mechanical design”. Journal of Guangxi University (Nat Sci Ed), vol.27, pp.93-97, June 2002. (In Chinese)

[5]. Yin Xiao-Zhong, Chen Xing-He. "On the curriculum reform of mechanical manufacturing technology". Journal of Zhen Jiang College, vol.23, A3, pp.92-94, July 2010. (In Chinese)

[6]. Bei Chun-Li. "The Development and Prospect of Chemistry in China". University Chemistry, vol.25, A2, pp. 1-10, 2000.

[7]. Bankel, J., Berggren K.F., Blom, K., Crawley, E.F., Wiklund, I. and Östlund, S., "The CDIO syllabus: a comparative study of expected student proficiency". European Journal of Engineering Education, vol.28, A3, pp. 297-315, 2003.

[8]. Chism N.V. "Classroom Assessment Techniques: A Handbook for College Teachers". Journal of Higher Education, vol.66, A1, pp. 427, 1993.

[9]. Massachusetts Institute of Technology, Chalmers University of Technology, Royal Institute of Technology, and Linköping Institute of Technology, "Improved Engineering Education: Changing the Focus towards Active Learning in a CDIO Context". Proposal submitted to the Knut and Alice Wallenberg Foundation, 10 May 2000. 